\title{
Nerve growth factor gene therapy improves bone marrow sensory innervation and nociceptor-mediated stem cell release in a mouse model of type 1 diabetes with limb ischaemia
}

\author{
Zexu Dang ${ }^{1}$ - Elisa Avolio ${ }^{1}$ - Ambra Albertario ${ }^{1} \cdot$ Graciela B. Sala-Newby $^{1}$ - Anita C. Thomas ${ }^{1} \cdot$ Nianhong Wang $^{1,2}$ • \\ Costanza Emanueli ${ }^{3}$. Paolo Madeddu ${ }^{1}$
}

Received: 7 August 2018 / Accepted: 4 March 2019 / Published online: 24 April 2019

(C) The Author(s) 2019

\begin{abstract}
Aims/hypothesis Sensory neuropathy is common in people with diabetes; neuropathy can also affect the bone marrow of individuals with type 2 diabetes. However, no information exists on the state of bone marrow sensory innervation in type 1 diabetes. Sensory neurons are trophically dependent on nerve growth factor (NGF) for their survival. The aim of this investigation was twofold: (1) to determine if sensory neuropathy affects the bone marrow in a mouse model of type 1 diabetes, with consequences for stem cell liberation after tissue injury; and (2) to verify if a single systemic injection of the $N G F$ gene exerts long-term beneficial effects on these phenomena.

Methods A mouse model of type 1 diabetes was generated in CD1 mice by administration of streptozotocin; vehicle was administered to non-diabetic control animals. Diabetic animals were randomised to receive systemic gene therapy with either human $N G F$ or $\beta$-galactosidase. After 13 weeks, limb ischaemia was induced in both groups to study the recovery post injury. When the animals were killed, samples of tissue and peripheral blood were taken to assess stem cell mobilisation and homing, levels of substance $\mathrm{P}$ and muscle vascularisation. An in vitro cellular model was adopted to verify signalling downstream to human $N G F$ and related neurotrophic or pro-apoptotic effects. Normally distributed variables were compared between groups using the unpaired Student's $t$ test and non-normally distributed variables were assessed by the Wilcoxon-Mann-Whitney test. The Fisher's exact test was employed for categorical variables.

Results Immunohistochemistry indicated a 3.3-fold reduction in the number of substance P-positive nociceptive fibres in the bone marrow of type 1 diabetic mice ( $p<0.001$ vs non-diabetic). Moreover, diabetes abrogated the creation of a neurokinin gradient which, in non-diabetic mice, favoured the mobilisation and homing of bone-marrow-derived stem cells expressing the substance P receptor neurokinin 1 receptor (NK1R). Pre-emptive gene therapy with NGF prevented bone marrow denervation, contrasting with the inhibitory effect of diabetes on the mobilisation of NK1R-expressing stem cells, and restored blood flow recovery from limb ischaemia. In vitro hNGF induced neurite outgrowth and exerted anti-apoptotic actions on rat PC12 cells exposed to high glucose via activation of the canonical neurotrophic tyrosine kinase receptor type 1 (TrkA) signalling pathway. Conclusions/interpretation This study shows, for the first time, the occurrence of sensory neuropathy in the bone marrow of type 1 diabetic mice, which translates into an altered modulation of substance P and depressed release of substance P-responsive stem cells following ischaemia. $N G F$ therapy improves bone marrow sensory innervation, with benefits for healing on the occurrence of peripheral ischaemia. Nociceptors may represent a new target for the treatment of ischaemic complications in diabetes.
\end{abstract}

Zexu Dang and Elisa Avolio contributed equally to this study.

Electronic supplementary material The online version of this article (https://doi.org/10.1007/s00125-019-4860-y) contains peer-reviewed but unedited supplementary material, which is available to authorised users.

Paolo Madeddu

mdprm@bristol.ac.uk

1 Experimental Cardiovascular Medicine, Faculty of Translational Health Sciences, Bristol Medical School, University of Bristol, Upper Maudlin Street, Bristol BS2 8HW, UK
2 Department of Rehabilitation Medicine, Huashan Hospital, Fudan University, Pudong, Shanghai, China

3 National Heart and Lung Institute, Imperial College London, London, UK 


\section{Research in context}

\section{What is already known about this subject?}

- Sensory neuropathy is a common complication of diabetes that is characterised by damage to the sensory nerves. This causes an altered pain perception and impairs the activation of healing mechanisms post injury

- Sensory neuropathy affects the bone marrow of individuals with type 2 diabetes, but no information exists on the state of bone marrow sensory innervation in type 1 diabetes

- Sensory neurons are trophically dependent on nerve growth factor (NGF) to survive

\section{What is the key question?}

- Does the administration of the NGF gene: (1) prevent sensory neuropathy in the bone marrow of type 1 diabetic mice; and (2) promote stem cell liberation to protect from tissue injury following peripheral ischaemia?

\section{What are the new findings?}

- Sensory neuropathy occurs in bone marrow in a mouse model of type 1 diabetes

- The consequences of sensory neuropathy are an altered modulation of the neuropeptide substance $P$, a reduction in substance P-positive nociceptive fibres in the bone marrow, a depressed release of substance P-responsive stem cells from the bone marrow following ischaemia and, eventually, a limited availability of healing cells homing into the ischaemic tissue

- NGF therapy improves bone marrow sensory innervation, restores proper stem cell release and benefits blood flow recovery after induction of limb ischaemia

\section{How might this impact on clinical practice in the foreseeable future?}

- Prophylactic treatment of sensory neuropathy by neurotrophic factor therapy could be a viable option for alleviating neurotrophic complications in type 1 diabetes, and nociceptors may represent a new target for the treatment of ischaemic complications

Keywords Bone marrow $\cdot$ Bone marrow stem cells $\cdot$ Gene therapy $\cdot$ Nerve growth factor $\cdot$ Nociceptor $\cdot$ PC12 cells $\cdot$ Peripheral ischaemia $\cdot$ Sensory neuropathy $\cdot$ Substance $P \cdot$ Type 1 diabetes

$\begin{array}{ll}\text { Abbreviations } \\ \text { Ad. } \beta G a l & \text { Adenovirus carrying the } \beta \text {-galactosidase gene } \\ \text { Ad.hNGF } & \text { Adenovirus carrying the human } N G F \text { gene } \\ \text { CREB } & \text { cAMP response element binding protein } \\ \text { DRG } & \text { Dorsal root ganglia } \\ \text { ERK1/2 } & \text { Extracellular signal-regulated kinases 1/2 } \\ \text { GDNF } & \text { Glial-cell-line-derived neurotrophic factor } \\ \text { JNK } & \text { Jun N-terminal kinase } \\ \text { LSK } & \text { Lineage }^{-} \text {Sca- } 1^{+} \text {and c-Kit }{ }^{+} \text {cells } \\ \text { NGF } & \text { Nerve growth factor } \\ \text { NK1R } & \text { Neurokinin 1 receptor } \\ \text { P75 } & \text { p75 neurotrophin receptor } \\ \text { P-rpS6 } & \text { Phospho-ribosomal protein S6 } \\ \text { RET } & \text { Receptor for GDNF-family ligands } \\ \text { SAPK } & \text { Stress-activated protein kinase } \\ \text { STZ } & \text { Streptozotocin } \\ \text { TrkA } & \text { Neurotrophic tyrosine kinase receptor type 1 }\end{array}$

\section{Introduction}

Diabetes mellitus is a great challenge for the healthcare system, accounting for $\sim 6 \%$ of mortality in industrialised countries [1]. As many as $70 \%$ of people with diabetes are estimated to have some form of neuropathy, which often overlaps with, and worsens, the consequences of diabetic vascular disease $[2,3]$. Sensory neuropathy is a typical form of peripheral neuropathy, characterised by an altered perception of noxious stimuli and ischaemic pain [4-6]. Impaired nociception facilitates the insurgence of foot ulcers caused by pressure or traumas [4] and also abrogates warning symptoms during a heart attack [7].

Our group has recently reported that sensory neuropathy can occur in the bone marrow of mice and individuals with long-term type 2 diabetes. Importantly, sensory fibre rarefaction was associated with an impairment in the neurokinin gradient that triggers 

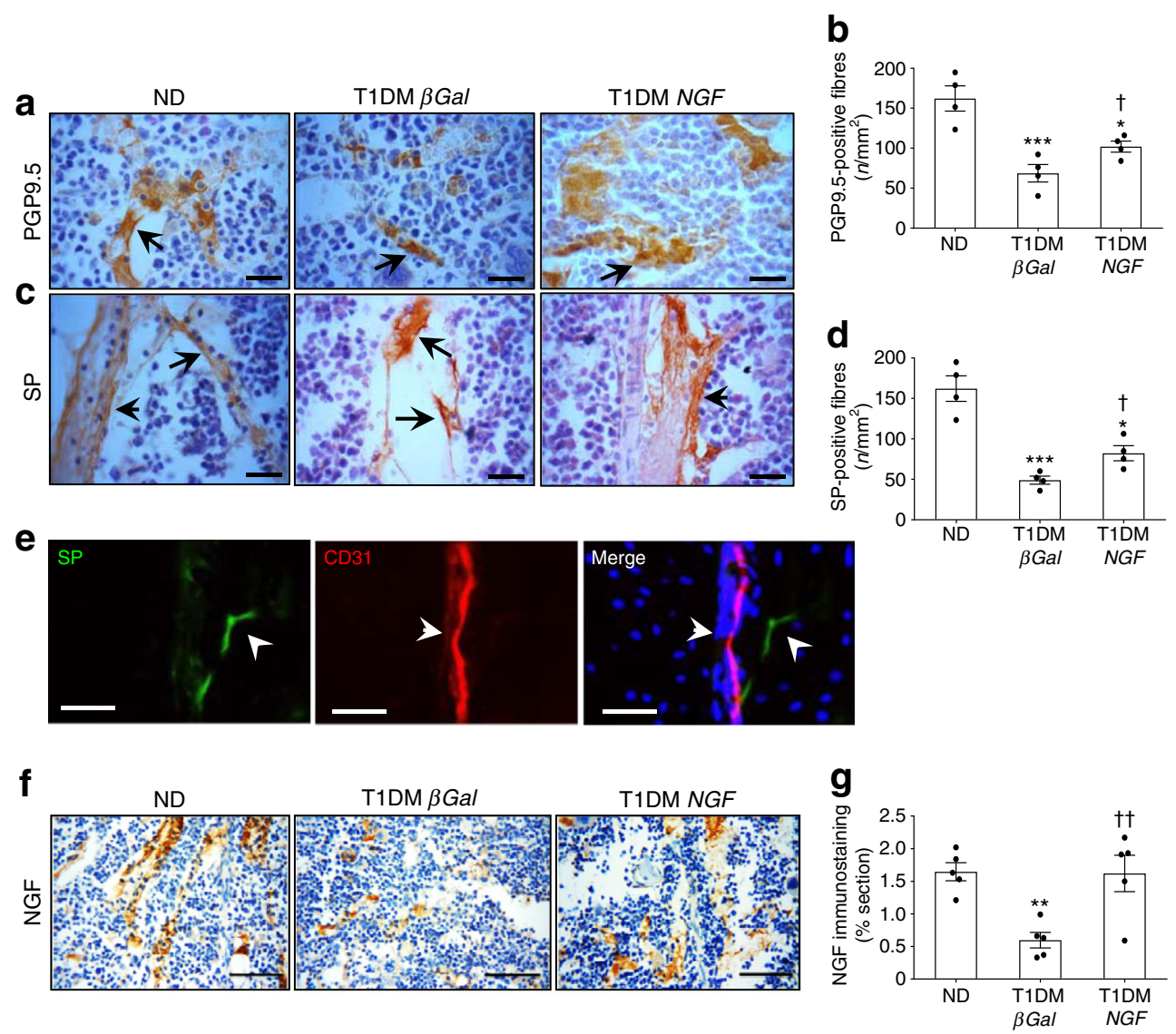

Fig. 1 Gene therapy with $N G F$ prevents bone marrow neuropathy. Immunohistochemical studies were carried out to compare the nerve fibre density in the bone marrow of non-diabetic and type 1 diabetic mice. The latter were randomised to receive Ad.hNGF or Ad. $\beta G a l$. (a-d) Representative micrographs and bar graphs showing the density of neuronal fibres expressing the pan-neuronal marker PGP9.5 (a, b) and nociceptive fibres positive for substance $\mathrm{P}(\mathbf{c}, \mathbf{d})$ (scale bar, $20 \mu \mathrm{m}$ ). Arrows point to positive fibres. (e) Representative immunofluorescence micro-

the release of bone-marrow-derived pro-angiogenic cells expressing the substance $\mathrm{P}$ neurokinin 1 receptor (NK1R) [8]. Nevertheless, no investigation has yet been conducted to ascertain the presence and consequences of bone marrow neuropathy in type 1 diabetes. This is an important issue as neuropathic complications are equally prevalent and therapeutically challenging in both types of diabetes [9].

Experimental and clinical evidence suggests that a deficit in neurotrophic factor signalling contributes to the pathogenesis of diabetic sensory $[10,11]$ and autonomic neuropathy [12]. Therefore, supplementation with neurotrophic factors, such as nerve growth factor (NGF) and glial-cell-linederived neurotrophic factor (GDNF), could be a viable option to treat neuropathic complications, with the only caveat that hyperalgesia has been reported as an occasional side effect of NGF in clinical trials $[13,14]$. scopy images identify substance P-containing sensory terminals, which were often associated with CD31-positive vascular structures (arrows) (scale bar, $50 \mu \mathrm{m}$ ). (f, g) Representative micrographs and bar graphs showing the density of NGF-positive neuronal fibres in bone marrow (scale bar, $50 \mu \mathrm{m}) . n=4$ per group $(\mathbf{b}, \mathbf{d}) ; n=5$ per group $(\mathbf{g})$. Data are expressed as means \pm SEM. ${ }^{*} p<0.05,{ }^{* *} p<0.01$ and ${ }^{* * * *} p<0.001$ vs non-diabetic animals; ${ }^{\dagger} p<0.05$ and ${ }^{\dagger \dagger} p<0.01$ vs type 1 diabetic mice with Ad. $\beta G a l$. ND, non-diabetic; SP, substance P; T1DM, type 1 diabetic

We have previously shown that NGF supplementation has pleiotropic therapeutic activities on nerves and vessels via a trophic signalling pathway comprising the neurotrophic tyrosine kinase receptor type 1 (TrkA), Akt and nitric oxide synthase (NOS), which overrides proNGF-induced activation of the pro-apoptotic $\mathrm{p} 75$ neurotrophin receptor $\left(\mathrm{p} 75^{\mathrm{NTR}}\right)[15,16]$ (this dual opposing mechanism is schematically illustrated in electronic supplementary material [ESM] Fig. 1). We were also the first to demonstrate that adenovirus (Ad)-mediated $N G F$ cardiac gene therapy induced the mobilisation and homing of pro-angiogenic bone-marrow-derived progenitor cells into ischaemic tissues $[17,18]$.

The aim of the present investigation was twofold: to determine the occurrence of sensory neuropathy in the bone marrow in a mouse model of type 1 diabetes (early stage) and to verify whether systemic $N G F$ gene therapy can prevent such a 
bone marrow pathology and the consequent defect in progenitor cell mobilisation following limb ischaemia.

\section{Methods}

An extended, detailed version of the methods is available as ESM. All manufacturers and suppliers are reported in the ESM. In in vitro experiments, each biological sample was assayed using 2-4 technical replicates, and the values average was used for statistical analysis. Randomisation did not apply to in vitro studies and experimenter blinding was not carried out.

Fig. 2 Gene therapy with $N G F$ activates TrkA signalling in sensory neurons and bone marrow cells of diabetic mice. (a, b) Representative immunofluorescence images showing that, 16 weeks post gene transfer, a higher number of substance P-positive sensory neuron bodies display phosphorylation of rpS6 in the DRG of diabetic mice receiving V5-tagged Ad.h $N G F$ (a) compared with diabetic mice receiving Ad. $\beta G a l$ (b). Scale bar, $100 \mu \mathrm{m}$. (c, d) Representative immunofluorescence images showing that, in bone marrow of $\mathrm{h} N G F$-treated mice, a higher number of cells are characterised by phosphorylation of $\mathrm{rpS} 6(\mathbf{c})$ compared with control mice receiving $\beta G a l$ (d). Scale bar, $50 \mu \mathrm{m}$. In all images, phosphorpS6 is shown in green, substance $\mathrm{P}$ in red. DAPI, in blue, identifies nuclei. $n=3$ mice, Ad.h $N G F$ and $n=3$ mice, Ad. $\beta$ Gal. $\mathrm{BM}$, bone marrow; SP, substance P

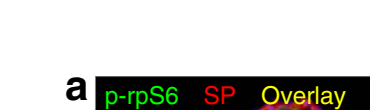

In vivo model of type 1 diabetes, limb ischaemia and gene therapy The experimental protocol is summarised in ESM Fig. 2.

Type 1 diabetes was induced in male 7-week-old CD1 mice by intraperitoneal injection of streptozotocin (STZ). CD1 is a multipurpose mouse model, using an outbred and genetic stable strain, and is available from Charles River for biomedical research; the full name is Crl:CD1(ICR). Mice with STZinduced diabetes develop a form of neuropathy like that seen in individuals with type 1 diabetes. Age-matched male CD1 mice injected with STZ vehicle were used as non-diabetic control animals. At 2 weeks after the first STZ injection, only mice that had developed diabetes were included in the study,

matro

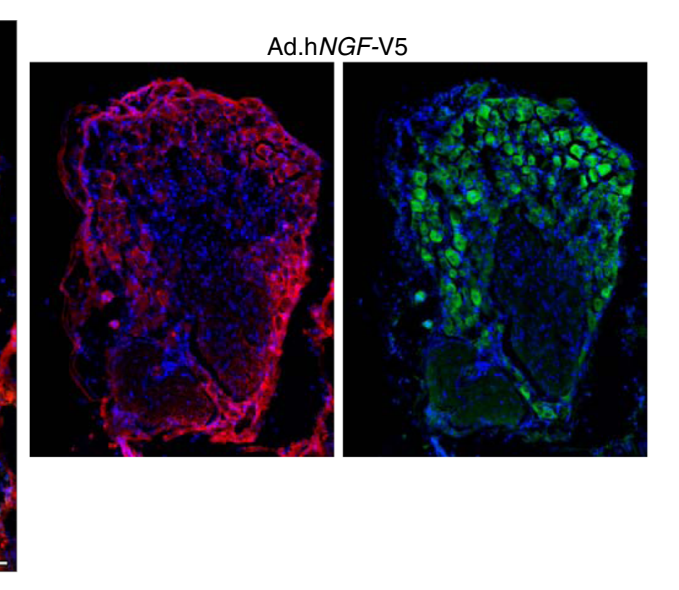

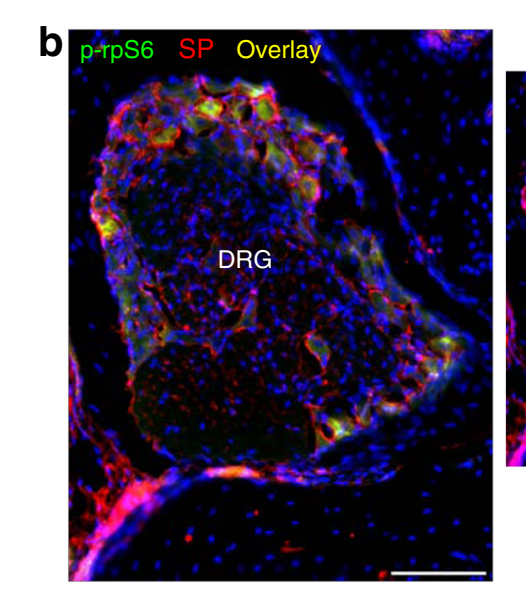

C

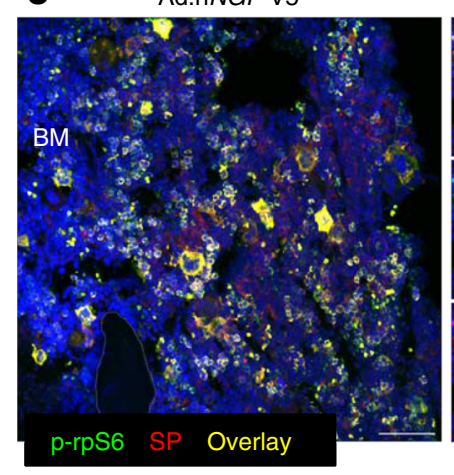

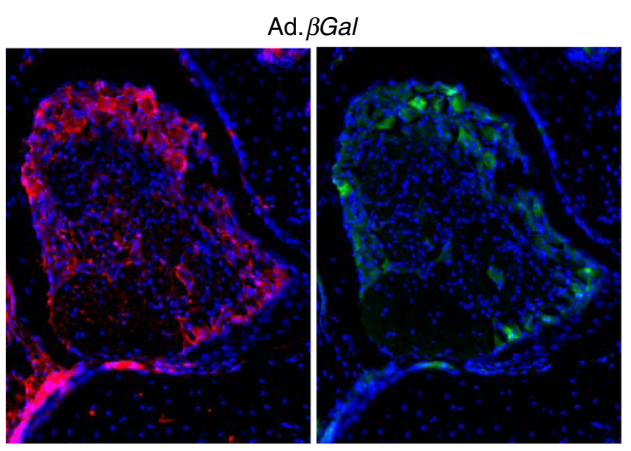

d

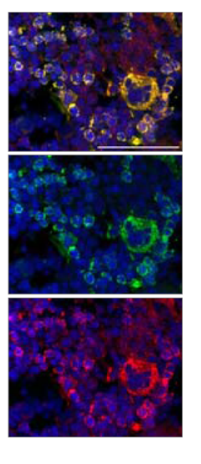

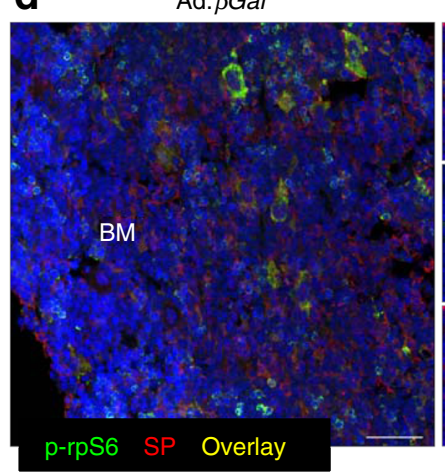

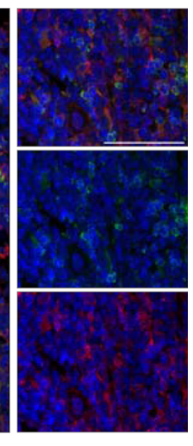


a

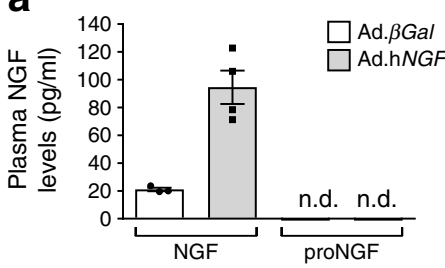

b
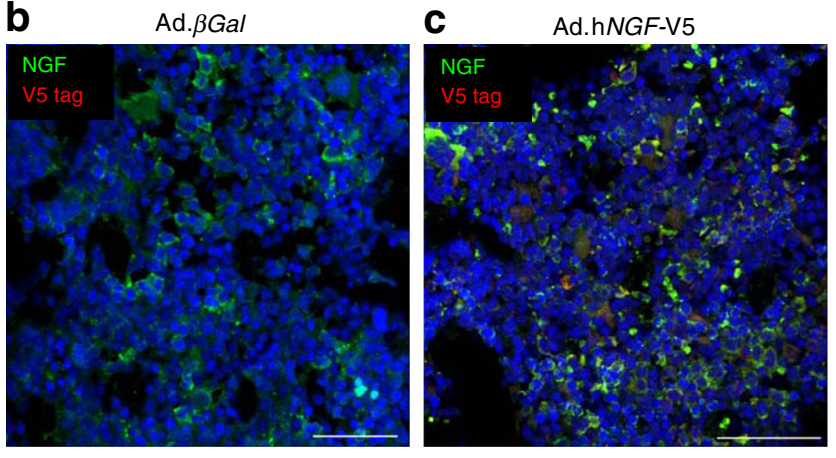

d

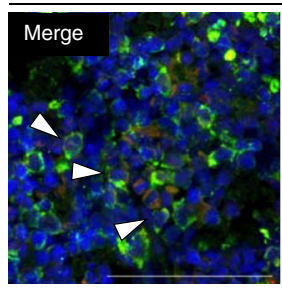

Ad.hNGF-V5
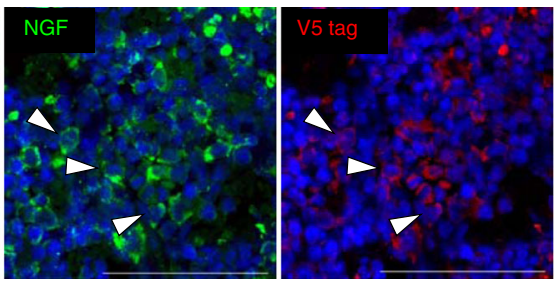

Fig. 3 Expression of recombinant hNGF in mouse plasma and bone marrow. (a) The expression of NGF and proNGF was measured by ELISA assay in mouse plasma 3 days post gene transfer $(n=4$ Ad.h $N G F$ and $n=3$ Ad. $\beta G a l)$. Data are expressed as means \pm SEM. (b-d) The recombinant V5-tagged hNGF was detected by immunofluorescent staining in bone marrow cells of mice receiving gene therapy, at the end of the experimental procedure (16 weeks post gene transfer). Animals given Ad. $\beta$ Gal served as a negative control for the V5 staining. V5 is shown in red, NGF in green, and blue (DAPI) shows nuclei. Arrows point to some examples of double-positive cells. Scale bar, $50 \mu$ m. n.d., not detected

underwent randomisation to two experimental groups and were injected with either adenovirus carrying the human $N G F$ gene (Ad.h $N G F$ ) or adenovirus carrying the $\beta$ galactosidase gene (Ad. $\beta G a l ; \beta G a l$ is also known as $G l b 1$ ) via the tail vein (total dose of $1.5 \times 10^{9}$ viral particles in $100 \mu \mathrm{l})$. Age-matched non-diabetic mice were used for reference samples collected after 16 weeks.

In a second set of experiments, unilateral limb ischaemia was induced in mice 13 weeks after gene delivery. Animals were killed at $0,1,3,7,14$ and 21 days after limb ischaemia.

An additional set of CD1 mice were given Ad.hNGF or Ad. $\beta$ Gal and plasma was collected 3 days later for assessment of hNGF overexpression.

Immunohistochemistry and immunofluorescence microscopy Bone marrow neuronal fibres, NGF, V5-tag, substance P and phospho-ribosomal protein S6 (phospho-rpS6) were evaluated in bone marrow sections or dorsal root ganglia. Capillary and arteriole densities were quantified in muscle sections. The specificity of the anti-NGF antibody was confirmed with a competitive assay using an NGF peptide.

ELISA ELISAs for hNGF, pro-hNGF and substance $\mathrm{P}$ were performed on plasma, bone marrow or ischaemic adductor muscles.

Rat fibroblast transduction and collection of conditioned media Primary rat fibroblasts were transduced with either Ad.hNGF or Ad. $\beta G a l$. Cells not transduced served as control (non-virus). After $48 \mathrm{~h}$, the conditioned medium was collected and used for subsequent studies with rat PC12 cells (a neuronal cell line derived from a pheochromocytoma of the rat adrenal medulla).

Biological assays on PC12 cells exposed to the conditioned media from NGF-transduced fibroblasts To test the biological effects of hNGF, PC12 cells were pre-conditioned for $48 \mathrm{~h}$ with basal- or high-glucose medium $(5 \mathrm{mmol} / \mathrm{l}$ and $30 \mathrm{mmol} / \mathrm{l}$, respectively) and exposed to conditioned medium from fibroblasts previously transduced with either Ad.hNGF or Ad. $\beta G a l$. Whole cell protein extracts were collected for signalling studies by western blotting. Apoptosis and neuronal differentiation experiments were performed.

Flow cytometry on peripheral blood progenitor cells Analyses of progenitor cell phenotype in peripheral blood, bone marrow and adductor muscles of mice were conducted using multicolour flow cytometry.

Bone marrow cell migration To verify the effect of type 1 diabetes on the sensitivity of bone marrow cells to substance $\mathrm{P}$, in vitro migration assays of freshly isolated bone marrow cells to substance $\mathrm{P}$ were performed.

Ethics approval and consent to participate Experiments involving live animals were performed in accordance with the Guide for the Care and Use of Laboratory Animals (Institute of Laboratory Animal Resources, 1996) and with approval from the British Home Office and the University of Bristol.

Statistical analysis The D'Agostino and Pearson omnibus normality test was applied to check for normal distribution of data. Normally distributed continuous variables were expressed as mean \pm SEM and compared between groups using the unpaired Student's $t$ test. When continuous variables did not follow a normal distribution, values were expressed as median (interquartile range [IQR]) and compared using the Wilcoxon-Mann-Whitney test. Categorical variables were compared using the $\chi^{2}$ or Fisher's exact test. All reported 

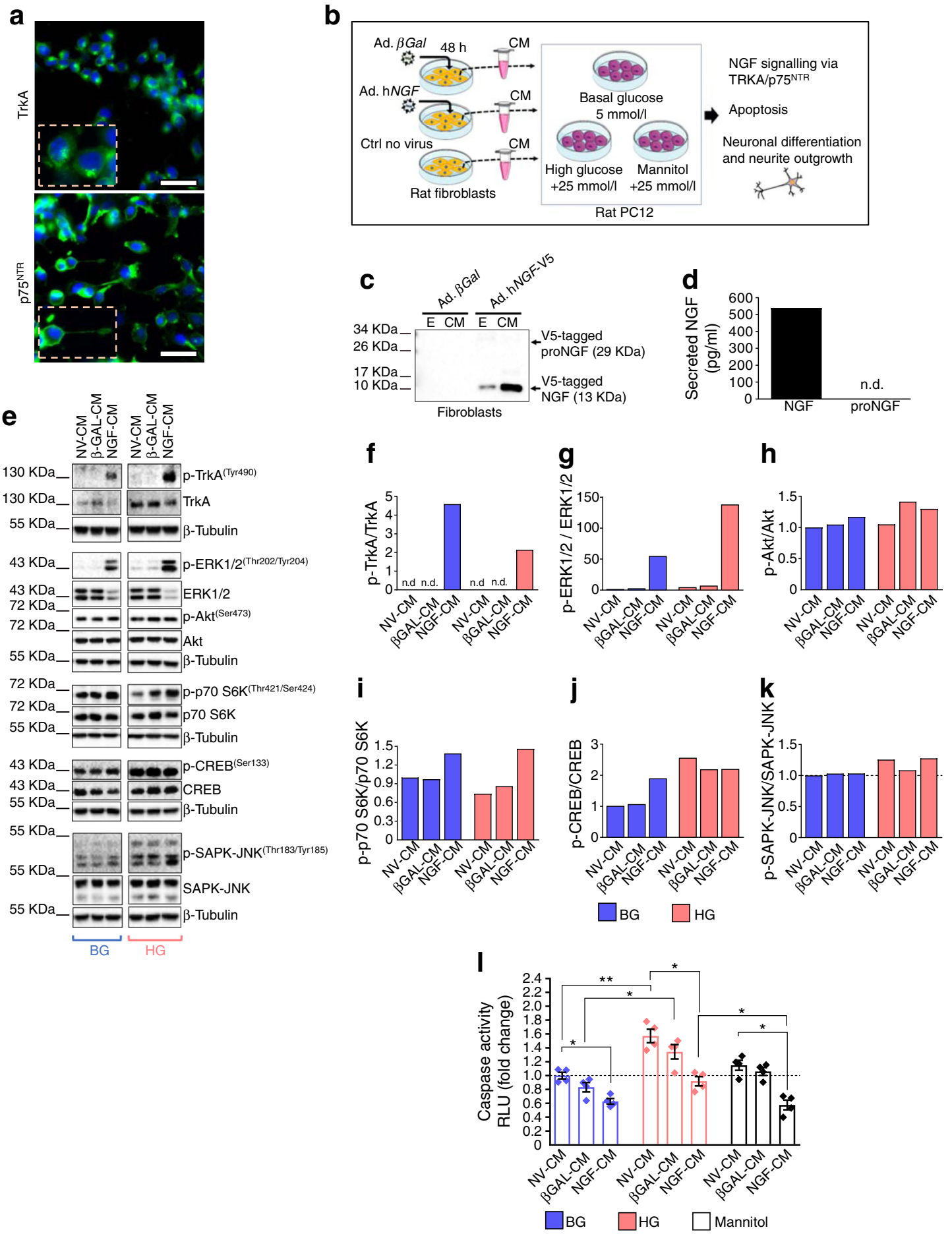

$p$ values are two sided. A $p$ value $<0.05$ was considered statistically significant.

\section{Results}

Rarefaction of nociceptive innervation in bone marrow from type 1 diabetic mice We first compared the abundance of nerve fibres in the bone marrow of mice with early-stage type 1 diabetes and non-diabetic control animals using immunohistochemical techniques described previously $[19,20]$. Figure $1 \mathrm{a}, \mathrm{c}$ shows fibres that express the pan-neuronal markers PGP9.5 and substance $P$ in the central part of the bone cavity and the periosteum. Morphometric analyses showed that diabetes induces a marked reduction in the density of both PGP9.5-positive fibres (Fig. 1b, $p<0.001$ vs non-diabetic 
Fig. 4 hNGF exerts neuroprotective effects in PC12 cells in vitro. (a) PC12 cells express the NGF receptors TrkA and $\mathrm{p} 75^{\mathrm{NTR}}$ (green). DAPI identifies nuclei (blue). Scale bar, $50 \mu \mathrm{m}$. (b) Schematic showing the experimental model. Rat fibroblasts were transduced with Ad.hNGF or Ad. $\beta$ Gal; non-transduced cells served as the control. Conditioned medium from fibroblasts was collected after $48 \mathrm{~h}$ and used to mimic the paracrine action of circulating NGF on target PC12 cells in a basal- or high-glucose environment, or with mannitol as osmotic control. Endpoints of the experiments were NGF intracellular signalling, apoptosis assay and neural differentiation. (c) V5-tagged hNGF was detected by western blotting in fibroblast total cellular extracts and conditioned medium. Only the mature NGF was detected, indicating that preproNGF was successfully cleaved to the mature form. (d) ELISA detected $540 \mathrm{pg} / \mathrm{ml}$ mature NGF in the fibroblast-conditioned medium used for the experiments. No proNGF was detected. (e) Blots for phospho-proteins and corresponding non-phosphorylated forms associated with pro-survival TrkA and pro-apoptotic $\mathrm{p} 75^{\mathrm{NTR}}$ signalling. (f-k) Graphs showing blot densitometry $(n=1)$. In $(\mathbf{g}-\mathbf{k})$, values are expressed as fold change of the basal glucose non-virus-conditioned medium. (l) Bar graph showing caspase 3/7 activity in PC12 exposed to either basal or high glucose or mannitol, for $48 \mathrm{~h}$, in the presence of fibroblast-conditioned medium. Caspase activity, measured as relative luminescence units, is expressed as fold change of the basal glucose non-virus-conditioned-medium group ( $n=4$ per group). Data are expressed as means \pm SEM. ${ }^{*} p<0.05$ and ${ }^{* *} p<0.01$ between groups, as indicated. BG, basal glucose; CM, conditioned medium; Ctrl, control; E, total cellular extract; HG, high glucose; n.d., not detected; $\mathrm{NV}$, non-virus; RLU, relative luminescence units

animals) and substance P-containing sensory terminals (Fig. $1 \mathrm{~d}, p<0.001$ vs non-diabetic animals).

Using immunofluorescence microscopy, we recognised that substance P-containing sensory terminals were often associated with CD31-positive vascular structures (Fig. 1e). In addition, substance P-positive sensory fibres in the bone marrow express the neurotrophic factor receptors TrkA, $\mathrm{p} 75^{\mathrm{NTR}}$ and receptor for GDNF-family ligands (RET) (ESM Fig. 3). Specificity of the substance $\mathrm{P}$ immunofluorescent signal was confirmed in spinal cord sections, where substance $\mathrm{P}$ was found typically localised in dorsal root ganglia (ESM Fig. 4).

\section{Systemic NGF gene therapy prevents bone marrow neuropa-} thy NGF reportedly produces a robust regeneration of peripheral nociceptive axons [21]. To investigate whether $N G F$ gene therapy prevents bone marrow sensory neuropathy, we delivered an Ad.h $N G F$ construct, described previously [18, 22], to mice intravenously, 2 weeks after induction of diabetes by STZ. After 16 weeks, bone marrow and spinal cord were collected to perform immunohistochemical studies. Interestingly, $N G F$ gene therapy prevented the reductive effect of diabetes on PGP9.5- and substance P-positive fibre density (Fig. 1a-d, $p<0.05$ vs $\beta G a l$ mice for both comparisons). Also, we found that NGF protein expression is downregulated in bone marrow nerves of diabetic mice compared with nondiabetic mice (Fig. 1f, g, $p<0.01$ ). The co-expression of NGF and PGP9.5 by neuronal fibres was verified in consecutive bone marrow sections (ESM Fig. 5). The hNGF gene transfer was able to restore normal NGF levels in bone marrow
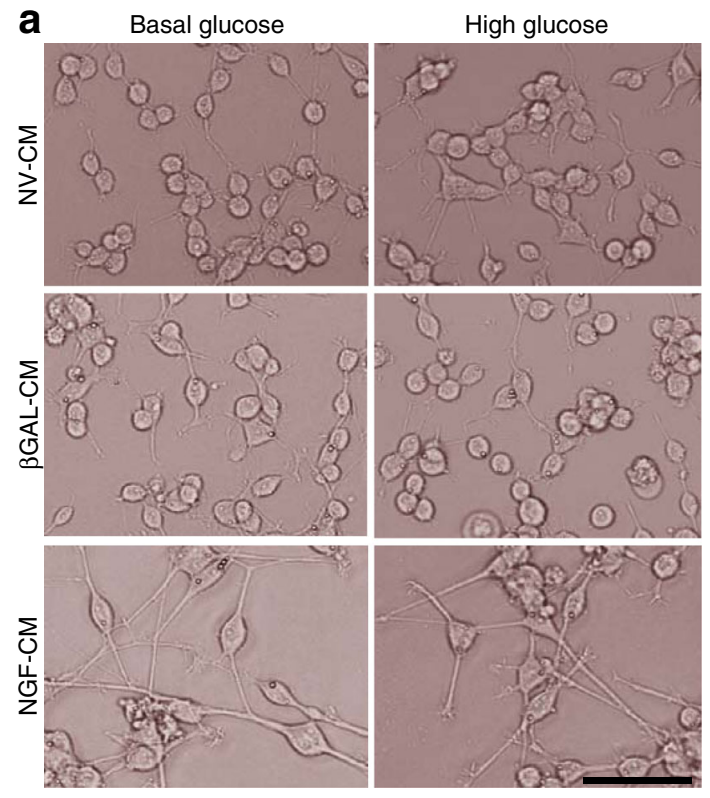

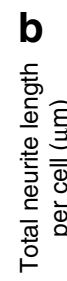

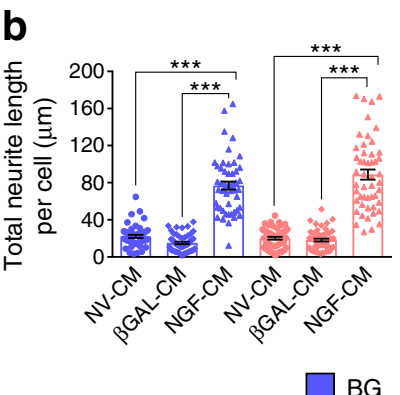

C

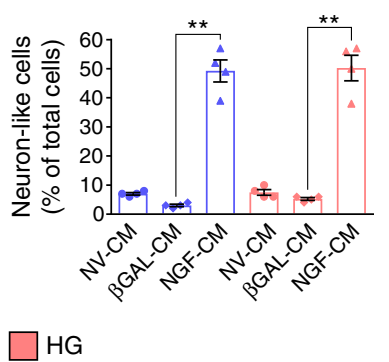

Fig. 5 hNGF induces neuronal differentiation of PC12 cells in vitro. (a) Bright-field images showing that $\mathrm{PC} 12$ cells differentiate into neuron-like cells in the presence of hNGF for 3 days, in either basal- or high-glucose environments (for the schematic of the experiment, please see Fig. 4b). Scale bar, $50 \mu \mathrm{m}$. (b) Graph showing the total neurite length per cell $(n=$ 50 cells per group assessed in four different imaging fields). (c) Graph showing the percentage of neuron-like cells, defined as cells presenting at least one axon longer than the cell body ( $n=4$ different imaging fields per group, for a total of $n=250-300$ cells assessed per group). Data are expressed as means \pm SEM. ${ }^{* *} p<0.01$ and ${ }^{* * *} p<0.001$ between groups, as indicated. Blue bars/symbols, basal glucose; pink bars/symbols, high glucose. BG, basal glucose; CM, conditioned medium; HG, high glucose; NV, non-virus

neuronal fibres (Fig. 1f, g, $p<0.01$ vs diabetic mice given $\beta G a l])$. Together, these results indicate that $N G F$ gene therapy can prevent neuropathy in diabetic bone marrow.

We then confirmed that NGF overexpression activated the TrkA signalling in the sensory neurons, and with this aim, we analysed the cell bodies of sensory neurons located in the dorsal root ganglia (DRG). At 16 weeks post gene therapy, we observed that a higher number of substance P-positive neurons showed phosphorylation of ribosomal protein S6 (P-rpS6) in diabetic animals receiving $\mathrm{hNGF}$ compared with diabetic mice receiving $\beta G a l$ (Fig. 2a, b). Also, we observed a higher number of cells co-expressing substance P and P-rpS6 

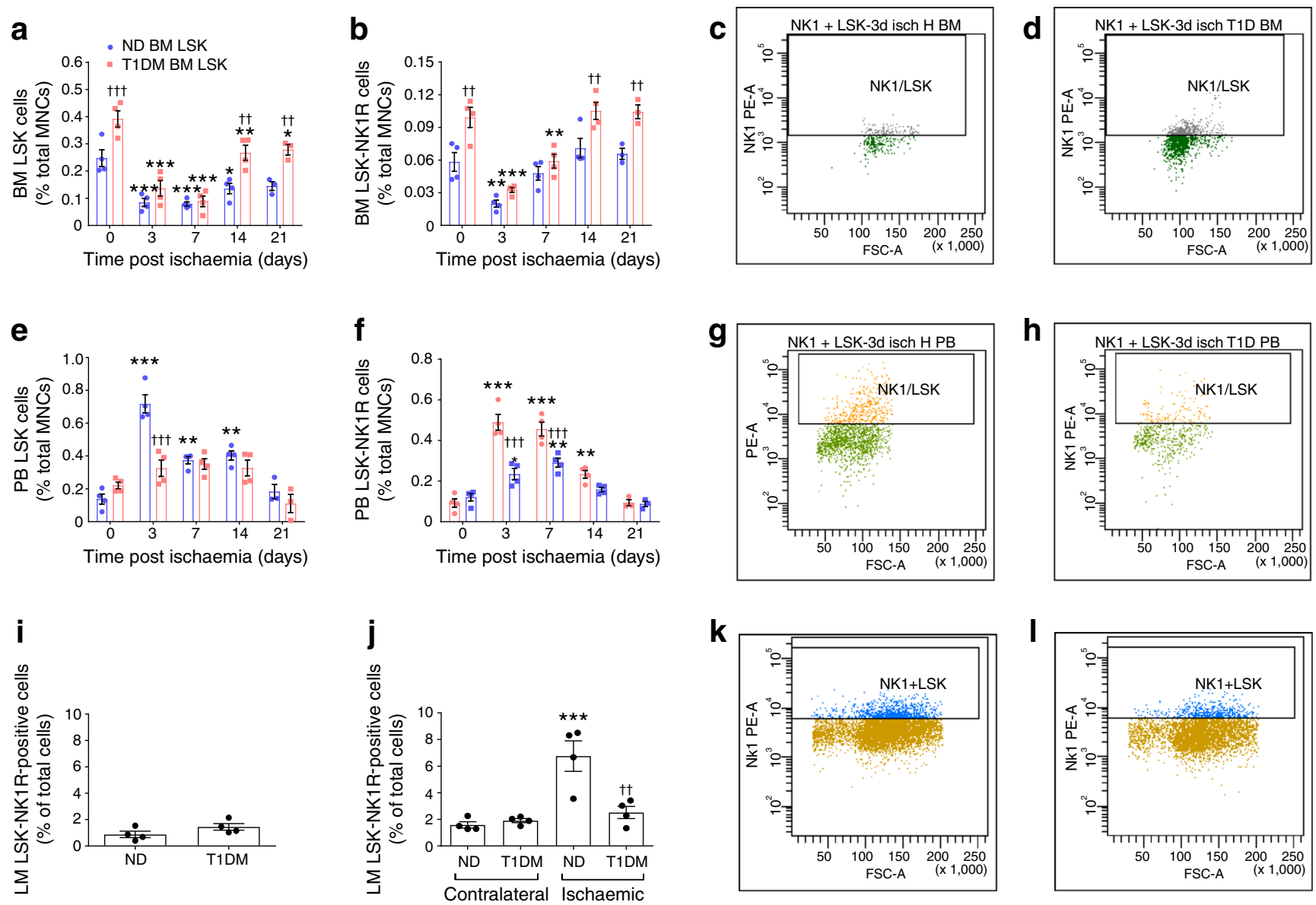

Fig. 6 Impaired liberation and homing of nociceptor-expressing cells in type 1 diabetic mice subjected to unilateral limb ischaemia. (a-h) Flow cytometry analyses showing the abundance of LSK and LSK-NK1 R cells in the bone marrow $(\mathbf{a}-\mathbf{d})$ and peripheral blood $(\mathbf{e}-\mathbf{h})$ of non-diabetic and type 1 diabetic mice before and after induction of limb ischaemia. Data are expressed as percentage of mononuclear cells. Representative images of gating performed on samples of bone marrow: (c) non-diabetic and (d) type 1 diabetic; and peripheral blood: (g) non-diabetic and (h) type 1 diabetic, collected at 3 days post limb ischaemia. $n=5$ mice per group; ${ }^{*} p<0.05,{ }^{* *} p<0.01$ and ${ }^{* * *} p<0.001$ vs time $0 ;{ }^{\dagger \dagger} p<0.01$ and ${ }^{\dagger \dagger} p<0.001$ vs non-diabetic animals. (i-l) Flow cytometry analyses of

k

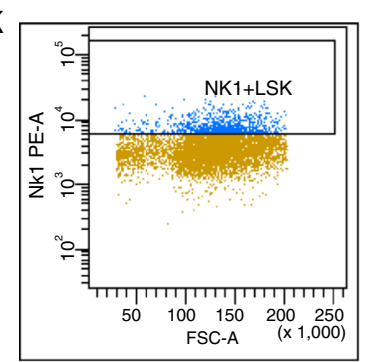

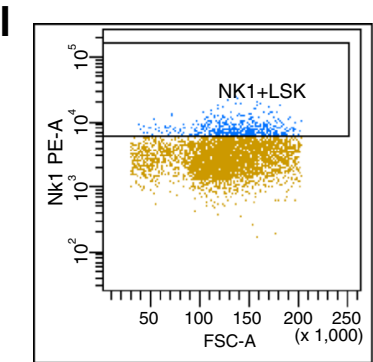

LSK-NK1R cells in murine muscles. Bar graphs showing the levels of LSK-NK1R cells in normoperfused limb muscles from non-operated mice (i), and LSK-NK1R cells in contralateral and ischaemic limb muscles collected 3 days post limb ischaemia from non-diabetic and type 1 diabetic mice (j). Typical gates of flow cytometry analyses performed on ischaemic limb muscles from non-diabetic (k) and type 1 diabetic (I) mice. $n=4$ per group. ${ }^{* * * *} p<0.001$ vs contralateral; ${ }^{\dagger} p<0.01$ vs nondiabetic. All data are expressed as means \pm SEM. BM, bone marrow; FSC-A, forward scatter-area; LM, limb muscle; MNC, mononuclear cell; ND, non-diabetic; PB, peripheral blood; PE-A, phycoerythrin area; T1DM, type 1 diabetic

hNGF-transduced cells exert paracrine-protective effects on PC12 cells We next performed in vitro assays on PC12 cells and verified that these cells express the NGF receptors TrkA and $\mathrm{p} 75^{\mathrm{NTR}}$ (Fig. 4a). Rat fibroblasts were transduced with either Ad.hNGF or Ad. $\beta G a l$ and their conditioned medium was used for conditioning PC12 cells under basal- or highglucose conditions (Fig. 4b). Results of western blotting confirmed the presence of hNGF in fibroblast-conditioned media (Fig. 4c), with immunoblotting with an anti-V5 tag antibody identifying a band of $13 \mathrm{kDa}$, corresponding to the mature hNGF in the conditioned medium and cell extracts. ProNGF was not detected, indicating that the recombinant protein is cleaved to its mature form as physiologically expected for the endogenous NGF. These results were further confirmed using ELISAs to identify the presence of NGF in the cell- 

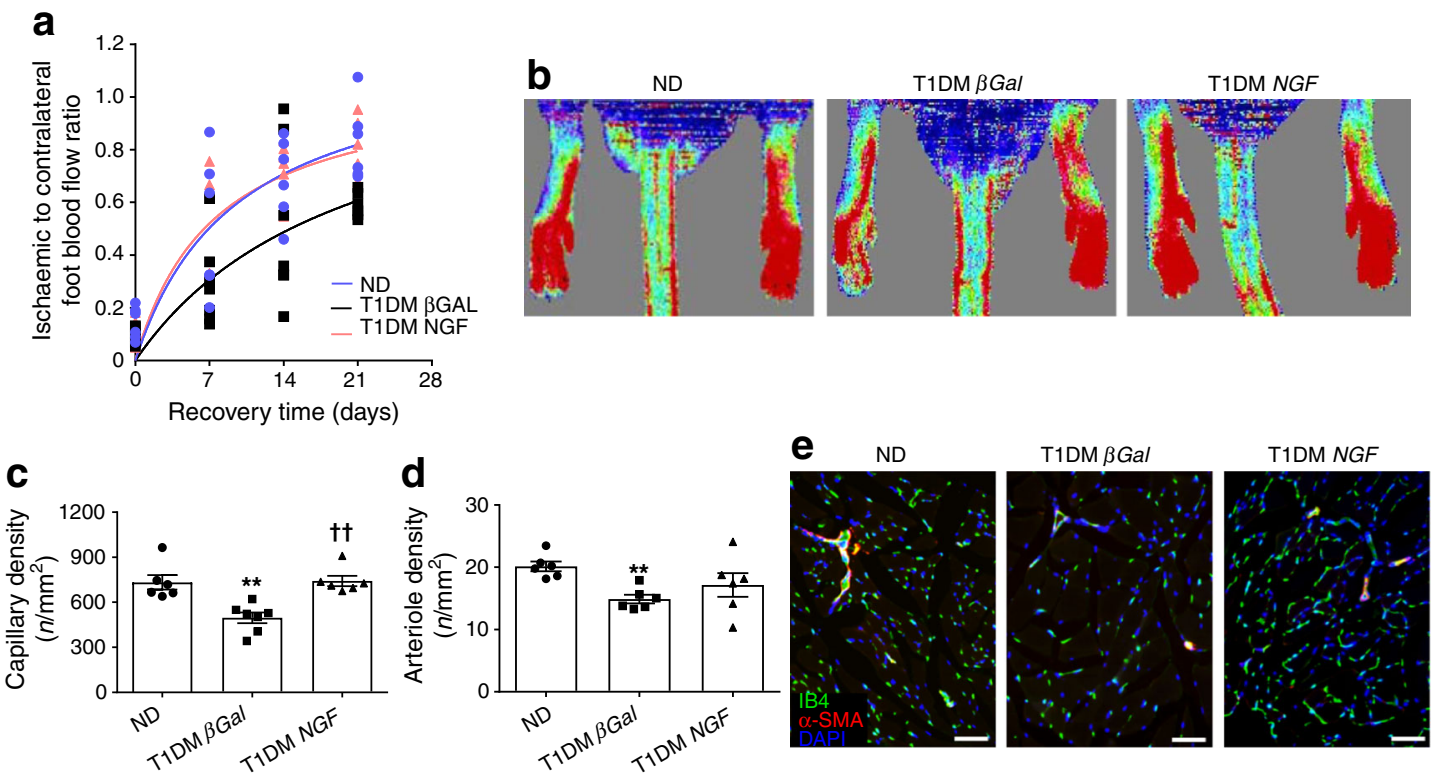

Fig. 7 Systemic $N G F$ therapy improves recovery from limb ischaemia. (a, b) Line graph (a) and representative laser Doppler images (b) of limb muscle reperfusion. (c-e) Bar graph (c, d) and representative fluorescent microphotographs (e) of capillary and arteriole density in limb muscles of non-diabetic and type 1 diabetic mice treated with Ad.hNGF or Ad. $\beta G a l$. (e) Capillary endothelial cells are stained with isolectin B4 (green) and arterioles with $\alpha$-smooth muscle actin (red). Nuclei are stained with DAPI

conditioned medium $(540 \mathrm{pg} / \mathrm{ml})$. In contrast, proNGF was not detected by the assay (Fig. $4 \mathrm{~d}$ ).

Western blot analyses showed that the conditioned medium of hNGF-transduced fibroblasts activated TrkA under conditions of either basal or high glucose, as indicated by the phosphorylation of tyrosine 490 (Fig. 4e, f). This event triggers the classic pro-survival signalling via TrkA in PC12 cells, as suggested by increased phosphorylation of extracellular signalregulated kinases 1/2 (ERK1/2), S6K and cAMP response element binding protein (CREB) compared with PC12 cells exposed to non-virus- and $\beta \mathrm{GAL}-$ conditioned medium; Akt phosphorylation was not relevantly modified at the time point assessed (Fig. 4e, g-j). We observed a slight increase in stressactivated protein kinase (SAPK)-Jun N-terminal kinase (JNK) phosphorylation in all groups exposed to high-glucose conditions (Fig. 4e). SAPK-JNK phosphorylation is involved in p $75^{\mathrm{NTR}}$ pro-apoptotic signalling [23]. However, we could not find any change in SAPK-JNK phosphorylation levels following the exposure of PC12 to NGF-conditioned medium (Fig. 4k) We also performed a caspase 3/7 assay in PC12 cells incubated with the fibroblast-conditioned medium for $48 \mathrm{~h}$, with either basal or high glucose levels, or mannitol as control (Fig. 41). We found that high glucose, but not treatment with the osmotic control mannitol, induced apoptosis in PC12 cells in the non-virus- and $\beta \mathrm{GAL}$-conditioned-medium groups $(p<0.01$ and $p<0.05$ vs corresponding basal glucose groups). Importantly, the conditioned medium of hNGFtransduced fibroblasts was able to prevent cell apoptosis in (blue). Scale bar, $50 \mu \mathrm{m}$. Bar graphs (c, d) summarise capillary and arteriole density data. In (c) $n=6$ per non-diabetic group and type 1 diabetic $N G F ; n=7$ per type 1 diabetic $\beta G a l$. In (d) $n=6$ per group. Data are expressed as means \pm SEM. ${ }^{* *} p<0.01$ vs non-diabetic; ${ }^{\dagger \dagger} p<0.01$ vs type 1 diabetic $\beta$ Gal. ND, non-diabetic; T1DM, type 1 diabetic

PC12 cells exposed to high glucose $(p<0.05, N G F$ vs nonvirus). It also reduced apoptosis in PC12 cells exposed to basal glucose or mannitol ( $p<0.05$ vs non-virus-conditioned medium, for both comparisons).

Finally, we tested the biological activity of the conditioned medium of $\mathrm{h} N G F$-transduced fibroblasts in a neural differentiation assay. As shown in Fig. 5a, this induced neurite outgrowth and differentiation of $\mathrm{PC} 12$ cells into neuron-like cells under either basal- or high-glucose conditions. The total neurite length per cell was significantly higher in the NGFconditioned-medium groups $(p<0.0001$ vs non-virusconditioned medium and $\beta$ GAL-conditioned medium) (Fig. $5 b)$. In addition, the number of neuron-like cells, identified as cells bearing at least one axon longer than the cell body, was significantly higher in the NGF-conditioned-medium groups $(p<0.01$ vs $\beta$ GAL-conditioned medium) (Fig. $5 \mathrm{c}$ ).

Taken together, these in vitro results corroborate the in vivo data, demonstrating that an environmental increase in NGF levels improves the growth and survival of neuronal cells.

Bone marrow sensory neuropathy is associated with the blunted release of nociceptor-positive progenitor cells following limb ischaemia Having demonstrated that type 1 diabetes induces structural alterations of bone marrow sensory innervation, we next asked if this neuropathology may have functional consequences for the release of haematopoietic progenitor cells following induction of tissue damage. We have previously shown that, in healthy mice, tissue ischaemia induces 

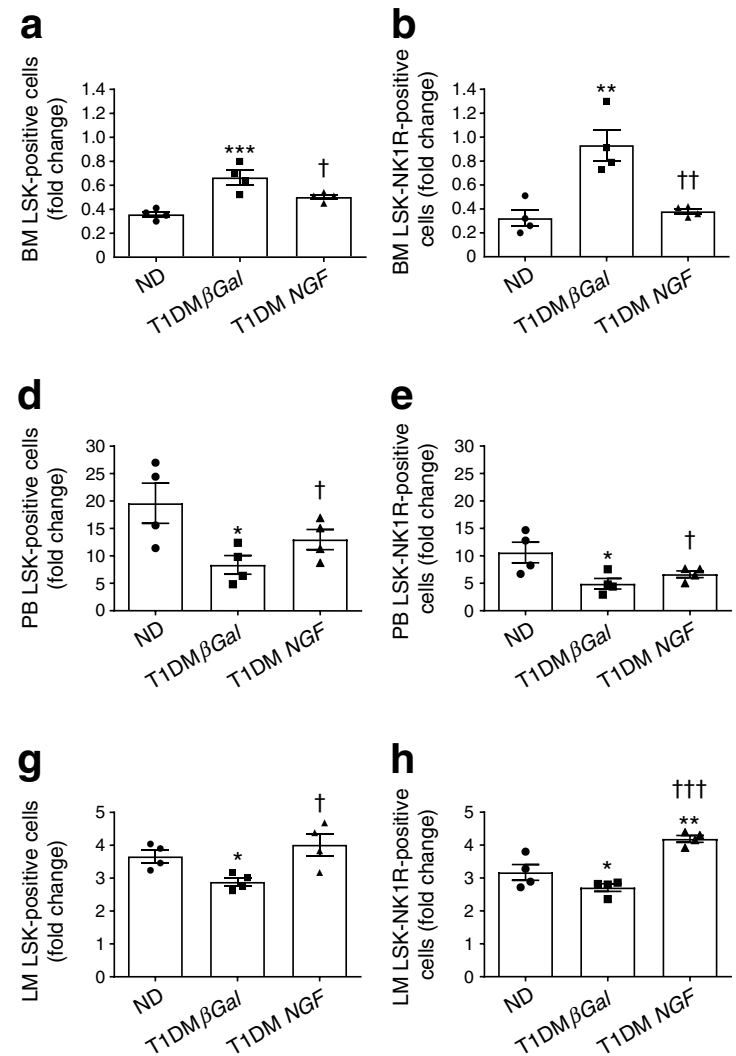

Fig. 8 Systemic $N G F$ therapy restores proper mobilisation of nociceptorexpressing cells in diabetic mice with limb ischaemia. (a-c) Bar graphs $(\mathbf{a}, \mathbf{b})$ and representative gating (c) from the flow cytometry analysis of bone marrow collected 3 days after limb ischaemia in non-diabetic and type 1 diabetic mice treated with Ad. $\beta G a l$ or Ad.hNGF. (d-f) Bar graphs (d, e) and representative gating (f) from the flow cytometry analysis of cells in peripheral blood collected 3 days after limb ischaemia. (g-i) Bar graphs (g, h) and representative gating (i) from the flow cytometry

the liberation of lineage ${ }^{-} \mathrm{Sca}^{+}{ }^{+}$and c-Kit ${ }^{+}$(LSK) cells coexpressing the substance P receptor NK1 (LSK-NK1R). This mechanism involves the activation of neuronal circuitry projecting from injured tissues to the bone marrow, which leads to the generation of a chemoattractant gradient of substance $\mathrm{P}$, favouring the movement of LSK-NK1R cells from bone marrow to peripheral tissue [24]. To determine if type 1 diabetes may affect this mechanism, we next performed flow cytometry quantification of LSK-NK1R cells in bone marrow and peripheral blood from non-diabetic and diabetic mice before and after unilateral limb ischaemia. The gating procedure is shown in ESM Fig. 7. As expected, diabetic mice showed retention of LSK and LSK-NK1R cells in bone marrow and blunted release of the same cells into the circulation $(p<0.001$ vs non-diabetic control animals for both cell types [Fig. $6 \mathrm{a}-$ h]). For precise identification of the cells in limb muscle, we first performed flow cytometry analyses of digested adductor muscles harvested from non-ischaemic mice and found that resident LSK-NK1R cells were of low abundance in both nondiabetic and type 1 diabetic mice ( $\sim 1 \%$ of total cells) (Fig. 6i).

\section{C}
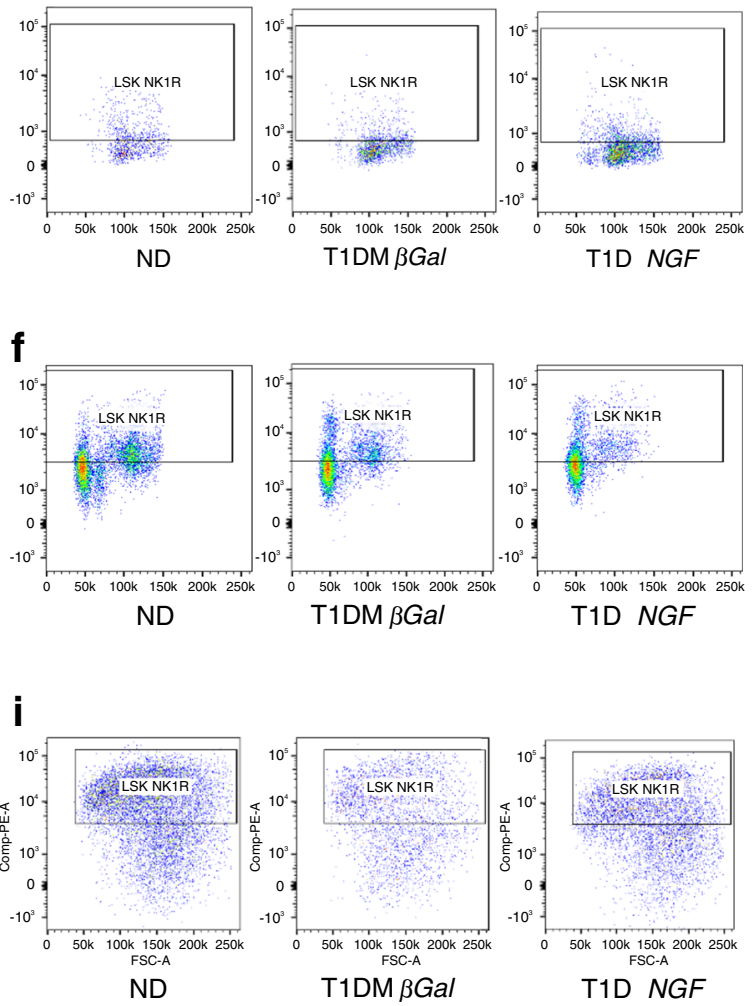

analysis of adductor limb muscles collected 3 days after limb ischaemia. Data are expressed as fold change in the number of positive cells vs preischaemia (a, b, d, e) or contralateral limb muscle (g, i). $n=4$ per group. Data are expressed as means \pm SEM. ${ }^{*} p<0.05,{ }^{* * *} p<0.01$ and ${ }^{* * *} p<0.001$ vs non-diabetic mice; ${ }^{\dagger} p<0.05,{ }^{\dagger \dagger} p<0.01$ and ${ }^{\dagger \dagger} p<0.001$ vs type 1 diabetic $\beta$ Gal mice. BM, bone marrow; LM, limb muscle; ND, non-diabetic; $\mathrm{PB}$, peripheral blood; T1DM, type 1 diabetic

We next assessed the homing of LSK-NK1R cells in ischaemic and contralateral muscles at 3 days post ischaemia, which corresponds to the peak of cell liberation into the circulation. Low levels of LSK-NK1R cells were detected in contralateral limb muscle with no difference between the non-diabetic and type 1 diabetic groups (Fig. 6j). Ischaemia increased the abundance of LSK-NK1R cells by 4.3 -fold in non-diabetic mice $(p<0.001 \mathrm{vs}$ contralateral), with this effect being remarkably reduced in diabetic mice ( $p<0.01$ vs non-diabetic mice, Fig. $6 j$ ). These data are also illustrated as representative flow cytometry images from ischaemic limb muscle of non-diabetic (Fig. 6k) and type 1 diabetic mice (Fig. 61).

Systemic gene therapy with NGF improves reparative processes and release of progenitor cells in diabetic mice with limb ischaemia Limb ischaemia was induced 13 weeks after gene delivery, with follow-up for 21 days. Compared with non-diabetic mice, diabetic mice showed delayed recovery of blood flow (Fig. 7a, b) and reduced reparative angiogenesis following induction of limb ischaemia (Fig. 7c-e). Pre- 

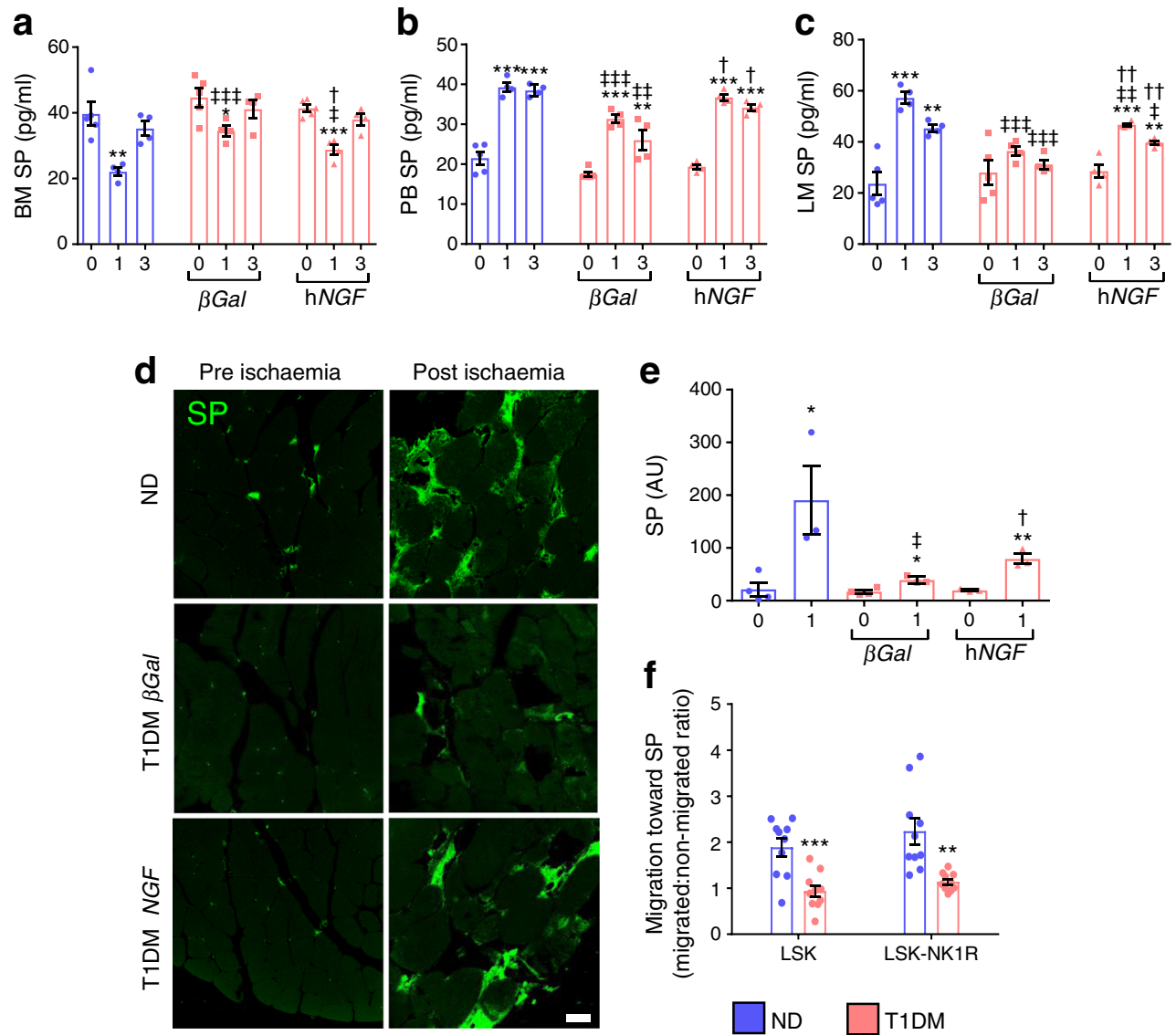

Fig. 9 Systemic $N G F$ therapy restores the substance $\mathrm{P}$ gradient in diabetic mice with limb ischaemia. (a-c) Bar graphs showing the results of ELISA measurements of substance $\mathrm{P}$ in bone marrow (a), peripheral blood (b) and limb muscles (c) before (day 0) and after (days 1 and 3) induction of limb ischaemia in non-diabetic and type 1 diabetic mice treated with Ad. $\beta G a l$ or Ad.hNGF. $n=5$ per non-diabetic group 0 and 3 days; $n=4$ per remaining groups. (d, e) Representative images (d) and bar graph (e) showing the expression of substance $\mathrm{P}$ in limb muscles before (day 0 ) and after limb ischaemia (day 1). Scale bar, $20 \mu \mathrm{m} . n=3$

emptive gene therapy with Ad.hNGF normalised the reperfusion and capillary density of ischaemic muscles compared with diabetic control mice (Fig. 7a-e).

We next investigated if gene therapy with $N G F$ rescues progenitor cell mobilopathy in diabetic mice. Flow cytometric quantification of LSK-NK1R cells was performed in bone marrow, peripheral blood and ischaemic adductor muscles of non-diabetic and diabetic mice at 3 days post ischaemia. As seen before, both LSK and LSK-NK1R cells were reduced following limb ischaemia in the bone marrow (Fig. 8a-c) and increased in peripheral blood (Fig. 8d-f) and ischaemic muscles (Fig. 8g-i) of non-diabetic mice, with these effects being blunted by type 1 diabetes (Fig. $8 \mathrm{a}-\mathrm{i}$ ). Ad.hNGF therapy promoted the mobilisation and homing of LSK and LSKNK1R cells (Fig. 8a-i). Measurement of substance P by ELISA showed a marked reduction in the neurokinin in bone marrow (Fig. 9a) and a concomitant increase in peripheral blood (Fig. 9b) and ischaemic muscles (Fig. 9c) of non- per group. ${ }^{*} p<0.05,{ }^{* *} p<0.01$ and ${ }^{* * *} p<0.01$ vs pre-ischaemia; ${ }^{\dagger} p<0.05$ and ${ }^{\dagger \dagger} p<0.01$ vs type 1 diabetic mice treated with Ad. $\beta G a l$; ${ }^{*} p<0.05,{ }^{+} p<0.01$ and ${ }^{+1+} p<0.001$ vs non-diabetic mice. (f) Bar graph showing the in vitro migration capacity of LSK and LSK-NK1R bone marrow cells from non-diabetic and type 1 diabetic mice towards substance P. $n=10$ per group; ${ }^{* *} p<0.01$ and ${ }^{* * * *} p<0.001$ vs non-diabetic mice. All data are expressed as means \pm SEM. AU, arbitrary units; BM, bone marrow; LM, limb muscle; ND, non-diabetic; $\mathrm{PB}$, peripheral blood; SP, substance P; T1DM, type 1 diabetic

diabetic mice. This mobilising gradient was blunted in diabetic mice and restored to normal by Ad.hNGF therapy (Fig. 9ac). We verified the expression and localisation of substance $P$ in limb muscles by immunohistochemistry (Fig. 9d). In nonischaemic skeletal muscle, substance $P$ expression was localised at the level of the microvasculature. At 1 day post ischaemia, substance $\mathrm{P}$ expression was increased and became more diffuse in non-diabetic mice, but the effect was blunted by type 1 diabetes (Fig. 9d, e). Ad.hNGF therapy induced upregulation of substance $\mathrm{P}$ in ischaemic muscles of diabetic mice (Fig. 9d, e).

As unresponsiveness to chemoattractants is a key determinant of the defective release of bone-marrow-derived progenitor cells in individuals with diabetes [25-27], we also investigated whether NK1R-expressing cells of diabetic mice became insensitive to substance $P$ stimulation. In line with this possibility, we found that the in vitro substance P-induced migration of bone marrow LSK-NK1R cells isolated from 
diabetic mice was remarkably reduced (Fig. 9f, $p<0.05$ vs non-diabetic mice). Therefore, in the type 1 diabetes model used in these experiments, two mechanisms may fail following ischaemia: the ability to create a gradient of substance $\mathrm{P}$ between peripheral tissue and bone marrow; and the capacity of NK1R cells to respond to substance P-induced chemoattraction. The in vivo experiment indicates that prevention of neuropathy by NGF allows for proper activation of bone marrow cell mobilisation.

\section{Discussion}

This study shows, for the first time, the presence of neuropathy involving NGF-dependent sensory neurons in bone marrow of type 1 diabetic mice. NGF supplementation prevents neuropathy, preserves the liberation of NK1R-expressing cells and benefits the recovery from ischaemia.

Previous work showed that physiological signalling through bone marrow adrenergic nerves regulates the circadian release of progenitor cells into the peripheral circulation $[27,28]$. Moreover, we were the first to report that specialised sensory receptors for detecting noxious stimuli play key roles in tissue healing. Specifically, ischaemic pain potently stimulates the release of nociceptor-expressing pro-angiogenic progenitor cells in mice and humans [24]. Blockade of the sensory circuit by the opioid agonist morphine or by cardiac denervation abolished progenitor cell release and homing to ischaemic tissues [24]. Moreover, mouse bone marrow reconstitution with nociceptor-knockout progenitor cells resulted in delayed the recovery blood flow and reduced neovascularisation after ischaemia [24]. This led us to hypothesise that the pain associated with a heart attack or acute injury is playing two roles, that is, it is acting as a sensor alarm and a switch for healing circuits. Some diabetic people experience 'silent' heart attacks because of sensory neuropathy, which may potentially leave them without those useful defence mechanisms [29]. Accordingly, we demonstrated that individuals with neuropathic type 2 diabetes do not release nociceptor-expressing progenitor cells from bone marrow under ischaemia or following granulocyte-colony stimulating factor (G-CSF) stimulation [8].

Sensory neuropathy is not an exclusive feature of elderly people with type 2 diabetes. A recent investigation of the participant to the SEARCH for Diabetes in Youth Study (SEARCH) estimated that the prevalence of neuropathy was $7 \%$ in young people with type 1 diabetes and $22 \%$ in young people with type 2 diabetes, but the difference was abrogated after adjustment for factors such as diabetes duration, blood pressure and waist circumference [9] The authors concluded that the early manifestation of neuropathy is a cause of concern and suggest that early screening and better risk factor management are needed.
Our findings add another piece of evidence about the deleterious effect of diabetes on bone marrow anatomy and function [30-32]. We show, for the first time, the presence of nociceptive fibre rarefaction in the bone marrow of young mice with STZ-induced type 1 diabetes. Diabetic mice had a 2.3-fold reduction in the density of fibres expressing the panneuronal marker PGP9.5 and a 3.3-fold decrease in nociceptive fibres positive for substance P and NGF, suggesting a more severe impact on sensory nerves. Substance P-positive sensory fibres were detected in the bone and around capillaries in the marrow parenchyma. This perivascular location is in keeping with the notion that nerves can regulate cell mobilisation from the bone marrow by influencing vascular permeability [27]. The anatomical alteration of bone marrow sensory innervation was associated with a reduced liberation of LSK cells that express the substance P receptor NK1R on induction of limb ischaemia. The basal levels of LSK-NK1Rpositive cells resident in limb muscles were very low, in the range of $1 \%$ of total isolated cells. It is well known that a small fraction of haematopoietic progenitor cells constantly circulate between the bone marrow and peripheral blood without any stimulation following a circadian rhythm [28]. It has also been proposed that several peripheral tissues, particularly peripheral fat, can constitute an extramedullary reservoir for functional haematopoietic stem and progenitor cells [33]. Our study suggests that the abundance of this resident population is not altered in the skeletal muscle of diabetic mice. On the other hand, the impact of type 1 diabetes on LSK-NK1Rpositive cells homing on limb ischaemia was remarkable, with abolition of muscular colonisation observed in non-diabetic control animals. This defective homing may have contributed to the poor angiogenic and perfusion recovery seen in diabetic mice. In fact, LSK-NK1R-positive cells possess proangiogenic and healing capacities and their abrogation by genetic or pharmacological approaches results in defective reparative angiogenesis [24]. The defective recruitment could be attributed to the incapacity of peripheral and bone marrow sensory neurons to coordinate a proper gradient of substance $P$ instrumental to the attraction of LSK-NK1R-positive cells, but also to an intrinsic lack of migratory capacity of these cells in response to chemoattractants, as observed in the in vitro assay of migration towards substance $P$.

The neurotrophic factor NGF supports neuronal survival and growth during prenatal development and maintains neuronal homeostasis postnatally through binding to TrkA [34]. In line with this, we observed that, in vivo, $N G F$ therapy activated the TrkA signalling, as shown by the phosphorylation of rpS6 in the cell bodies of substance P-positive sensory neurons. Moreover, our in vitro findings corroborate that increased environmental levels of hNGF promote neurite outgrowth, prevent apoptosis and stimulate the canonical signalling pathway downstream to TrkA, namely phosphorylation of ERK1/2, p70S6K and CREB. On the other hand, the main 
function of $\mathrm{p} 75$, which is the preferred receptor for proNGF, remains elusive. It has been shown to promote cell survival either in association with TRK receptors or by itself $[35,36]$ and also to induce apoptotic cell death [37,38]. Cell death induced by $\mathrm{p} 75$ reportedly requires c-JNK activation. In our investigation, the in vitro exposure of $\mathrm{PC} 12$ cells to high glucose slightly increased JNK phosphorylation. This effect of high glucose persisted following incubation of the same cells with the conditioned medium from Ad.h $N G F$-transduced fibroblasts, which was rich in mature NGF but not proNGF. On the other hand, the NGF-rich conditioned medium prevented the activation of apoptotic signalling induced by high glucose, as assessed by measurement of caspase 3/7 activity. Altogether, these data suggest that, in our experimental setting, induction of the survival signalling pathway, ERK1/2, p70S6K and CREB, rather than inhibition of p75/JNK, contributed to the improved survival of $\mathrm{PC} 12$ cells. Likewise, the protective effect of $N G F$ gene therapy is highlighted by its ability to contrast the rarefaction of substance P-positive fibres in mouse bone marrow.

In the last decade, some studies have investigated the potential therapeutic benefit of NGF in neuropathic conditions. Some clinical trials have indicated that NGF is safe and effective as a treatment for preventing progression of diabetic or human immunodeficiency virus-associated peripheral neuropathies at the highest dose of $0.3 \mu \mathrm{g} / \mathrm{kg}$ two or three times per week $[39,40]$. Another trial found no significant benefit in diabetic peripheral neuropathy at the dose of $0.1 \mu \mathrm{g} / \mathrm{kg}$ three times per week, thus suggesting a dose-related mechanism [39]. In line with this possibility, large improvements in pain intensity were observed following high-dose NGF [40]. Nevertheless, a controversy is emerging from preclinical and clinical trials regarding the potential for improvement or exacerbation of neuropathic pain with NGF therapy [41-43]. We did not perform behavioural tests in our study, and so the possibility that protection from sensory neuropathy is associated with neuropathic pain cannot be excluded.

We were the first to demonstrate that local supplementation of the NGF protein accelerates recovery from limb ischaemia by potentiation of skeletal muscle angiogenesis [15]. We have also shown that, in non-diabetic mice with myocardial infarction, systemic $N G F$ gene therapy promotes detachment of progenitor cells from the endosteal niche through activation of metalloproteinase-9 [18]. Here, we provide novel evidence that pre-emptive treatment with $N G F$ improves postischaemic blood flow recovery and restores proper neurokinin signalling instrumental to the release and homing of LSKNK1R-positive cells. A direct effect of NGF on muscle neovascularisation cannot be excluded. However, at variance from our previous studies in which NGF was administered as a protein or gene at the time of the ischaemia [15-18], here we administered $N G F$ therapy 13 weeks before the induction of ischaemia. Therefore, it is likely that the therapeutic effect is also attributable to preventive actions of NGF, one of which is protection against diabetes-induced bone marrow neuropathy. Although neuropathy does not directly cause vascular damage, the two conditions synergise in worsening diabetic foot complications.

In conclusion, we report that bone marrow neuropathy occurs early in the course of type 1 diabetes, resulting in alteration of pro-angiogenic cell capacity to migrate to sites of tissue injury. Pre-emptive gene therapy with $N G F$ corrected this defect and improved the recovery from limb ischaemia. Although acute occlusion of the femoral artery may not reflect chronic vascular disease occurring in people with diabetes, our findings suggest that prophylactic treatment of sensory neuropathy by neurotrophic factor therapy could be a viable option for alleviating neurotrophic complications in type 1 diabetes.

Acknowledgements The authors thank the British Heart Foundation and the Medical Research Council (both UK) for the financial support for this study.

The authors are grateful to the following individuals (all from the University of Bristol, Bristol, UK): S. Kasparov (School of Physiology, Pharmacology and Neuroscience) for the kind donation of PC12 cells; R. Ebrahimighaei and K. Ford (Translational Health Sciences) for their kind donation of rat fibroblasts; HM Martin and PB Savage (Translational Health Sciences) for their invaluable technical help with the preparation of histological samples.

We acknowledge staff at the Wolfson Bioimaging Facility of the University of Bristol for support with the confocal imaging.

Data availability The datasets used and/or analysed during the current study are available from the corresponding author on reasonable request.

Funding This study was funded by the British Heart Foundation programme grant RG/13/17/30545, 'Unravelling mechanisms of stem cell depletion for the preservation of regenerative fitness in patients with diabetes' and the UK Medical Research Council (grant MR/J002593/1), both to PM. The study was also supported by the British Heart Foundation Centre for Regenerative Medicine Award I (RM/13/2/ 30158) and British Heart Foundation Centre for Regenerative Medicine Award (II) ‘Centre for Vascular Regeneration' (RM/17/3/33381).

Duality of interest The authors declare that there is no duality of interest associated with this manuscript.

Contribution Statement ZD and PM conceived and designed the study. $\mathrm{ZD}$ and ACT performed in vivo experiments. ZD, EA, AA and NW acquired, and ZD, EA, ACT, GBS-N and PM analysed and interpreted, the data. GBS-N prepared the adenovirus. ZD, EA and PM drafted, and $\mathrm{CE}$ and PM critically revised, the manuscript. PM supervised the study and provision of funding. All authors read, revised and approved the final version of the manuscript. PM is responsible for the integrity of the work as a whole and is the guarantor of this work.

Open Access This article is distributed under the terms of the Creative Commons Attribution 4.0 International License (http:// creativecommons.org/licenses/by/4.0/), which permits unrestricted use, distribution, and reproduction in any medium, provided you give appropriate credit to the original author(s) and the source, provide a link to the Creative Commons license, and indicate if changes were made. 


\section{References}

1. (2008) The global challenge of diabetes. Lancet 371: 1723

2. Ismail-Beigi F, Craven T, Banerji MA et al Effect of intensive treatment of hyperglycaemia on microvascular outcomes in type 2 diabetes: an analysis of the ACCORD randomised trial. Lancet 376(9739):419-430. https://doi.org/10.1016/S0140-6736(10) 60576-4

3. Pop-Busui R, Evans GW, Gerstein HC et al Effects of cardiac autonomic dysfunction on mortality risk in the Action to Control Cardiovascular Risk in Diabetes (ACCORD) trial. Diabetes Care 33(7):1578-1584. https://doi.org/10.2337/dc10-0125

4. Boulton AJ, Vinik AI, Arezzo JC et al (2005) Diabetic neuropathies: a statement by the American Diabetes Association. Diabetes Care 28(4):956-962. https://doi.org/10.2337/diacare.28.4.956

5. Reinisch CM, Traxler H, Piringer S, Tangl S, Nader A, Tschachler E (2008) Rarefaction of the peripheral nerve network in diabetic patients is associated with a pronounced reduction of terminal Schwann cells. Diabetes Care 31(6):1219-1221. https://doi.org/ $10.2337 / \mathrm{dc} 07-1832$

6. Lennertz RC, Medler KA, Bain JL, Wright DE, Stucky CL (2011) Impaired sensory nerve function and axon morphology in mice with diabetic neuropathy. J Neurophysiol 106(2):905-914. https:// doi.org/10.1152/jn.01123.2010

7. Le Feuvre C, Jacqueminet S, Barthelemy O (2011) Myocardial ischemia: a silent epidemic in type 2 diabetes patients. Futur Cardiol 7(2):183-190. https://doi.org/10.2217/fca.10.127

8. Dang Z, Maselli D, Spinetti G et al (2015) Sensory neuropathy hampers nociception-mediated bone marrow stem cell release in mice and patients with diabetes. Diabetologia 58(11):2653-2662. https://doi.org/10.1007/s00125-015-3735-0

9. Jaiswal M, Divers J, Dabelea D et al (2017) Prevalence of and risk factors for diabetic peripheral neuropathy in youth with type 1 and type 2 diabetes: SEARCH for Diabetes in Youth Study. Diabetes Care 40(9):1226-1232. https://doi.org/10.2337/dc17-0179

10. Crowley C, Spencer SD, Nishimura MC et al (1994) Mice lacking nerve growth factor display perinatal loss of sensory and sympathetic neurons yet develop basal forebrain cholinergic neurons. Cell 76(6):1001-1011. https://doi.org/10.1016/0092-8674(94)90378-6

11. Anand P, Terenghi G, Warner G, Kopelman P, Williams-Chestnut RE, Sinicropi DV (1996) The role of endogenous nerve growth factor in human diabetic neuropathy. Nat Med 2(6):703-707. https://doi.org/10.1038/nm0696-703

12. Ieda M, Kanazawa $\mathrm{H}$, Ieda $\mathrm{Y}$ et al (2006) Nerve growth factor is critical for cardiac sensory innervation and rescues neuropathy in diabetic hearts. Circulation 114(22):2351-2363. https://doi.org/10. 1161/CIRCULATIONAHA.106.627588

13. Apfel SC, Schwartz S, Adornato BT et al (2000) Efficacy and safety of recombinant human nerve growth factor in patients with diabetic polyneuropathy: a randomized controlled trial. rhNGF Clinical Investigator Group. JAMA 284(17):2215-2221. https://doi.org/ 10.1001/jama.284.17.2215

14. McArthur JC, Yiannoutsos C, Simpson DM et al (2000) A phase II trial of nerve growth factor for sensory neuropathy associated with HIV infection. AIDS Clinical Trials Group Team 291. Neurology 54:1080-1088

15. Emanueli C, Salis MB, Pinna A, Graiani G, Manni L, Madeddu P (2002) Nerve growth factor promotes angiogenesis and arteriogenesis in ischemic hindlimbs. Circulation 106(17):22572262. https://doi.org/10.1161/01.CIR.0000033971.56802.C5

16. Salis MB, Graiani G, Desortes E, Caldwell RB, Madeddu P, Emanueli C (2004) Nerve growth factor supplementation reverses the impairment, induced by type 1 diabetes, of hindlimb postischaemic recovery in mice. Diabetologia 47:1055-1063
17. Meloni M, Caporali A, Graiani G et al (2010) Nerve growth factor promotes cardiac repair following myocardial infarction. Circ Res 106(7):1275-1284. https://doi.org/10.1161/CIRCRESAHA.109. 210088

18. Meloni M, Cesselli D, Caporali A et al (2015) Cardiac nerve growth factor overexpression induces bone marrow-derived progenitor cells mobilization and homing to the infarcted heart. Mol Ther 23(12):1854-1866. https://doi.org/10.1038/mt.2015.167

19. Chenu C (2004) Role of innervation in the control of bone remodeling. J Musculoskelet Nueronal Interact 4:132-134

20. Serre CM, Farlay D, Delmas PD, Chenu C (1999) Evidence for a dense and intimate innervation of the bone tissue, including glutamate-containing fibers. Bone 25(6):623-629. https://doi.org/ 10.1016/S8756-3282(99)00215-X

21. Lin CL, Heron P, Hamann SR, Smith GM (2014) Functional distinction between NGF-mediated plasticity and regeneration of nociceptive axons within the spinal cord. Neuroscience 272C:76-87

22. Hu X, Cai J, Yang J, Smith GM (2010) Sensory axon targeting is increased by NGF gene therapy within the lesioned adult femoral nerve. Exp Neurol 223(1):153-165. https://doi.org/10.1016/j. expneurol.2009.08.025

23. Kenchappa RS, Tep C, Korade Z et al (2010) p75 neurotrophin receptor-mediated apoptosis in sympathetic neurons involves a biphasic activation of JNK and up-regulation of tumor necrosis factor-alpha-converting enzyme/ADAM17. J Biol Chem 285(26): 20358-20368. https://doi.org/10.1074/jbc.M109.082834

24. Amadesi S, Reni C, Katare R et al (2012) Role for substance pbased nociceptive signaling in progenitor cell activation and angiogenesis during ischemia in mice and in human subjects. Circulation 125(14): 1774-1786. https://doi.org/10.1161/ CIRCULATIONAHA.111.089763

25. Fortunato O, Spinetti G, Specchia C, Cangiano E, Valgimigli M, Madeddu P (2013) Migratory activity of circulating progenitor cells and serum SDF-1alpha predict adverse events in patients with myocardial infarction. Cardiovasc Res 100(2):192-200. https://doi.org/ $10.1093 / \mathrm{cvr} / \mathrm{cvt} 153$

26. Fadini GP, Sartore S, Schiavon M et al (2006) Diabetes impairs progenitor cell mobilisation after hindlimb ischaemia-reperfusion injury in rats. Diabetologia 49(12):3075-3084. https://doi.org/10. 1007/s00125-006-0401-6

27. Ferraro F, Lymperi S, Mendez-Ferrer S et al (2011) Diabetes impairs hematopoietic stem cell mobilization by altering niche function. Sci Transl Med 3:104ra101

28. Scheiermann C, Kunisaki Y, Lucas D et al (2012) Adrenergic nerves govern circadian leukocyte recruitment to tissues. Immunity 37(2):290-301. https://doi.org/10.1016/j.immuni.2012. 05.021

29. Stratton IM, Adler AI, Neil HA et al (2000) Association of glycaemia with macrovascular and microvascular complications of type 2 diabetes (UKPDS 35): prospective observational study. BMJ 321(7258):405-412. https://doi.org/10.1136/bmj.321.7258. 405

30. Spinetti G, Cordella D, Fortunato O et al (2013) Global remodeling of the vascular stem cell niche in bone marrow of diabetic patients: implication of the microRNA-155/FOXO3a signaling pathway. Circ Res 112(3):510-522. https://doi.org/10.1161/CIRCRESAHA. 112.300598

31. Oikawa A, Siragusa M, Quaini F et al (2010) Diabetes mellitus induces bone marrow microangiopathy. Arterioscler Thromb Vasc Biol 30(3):498-508. https://doi.org/10.1161/ATVBAHA.109. 200154

32. Reni C, Mangialardi G, Meloni M, Madeddu P (2016) Diabetes stimulates osteoclastogenesis by acidosis-induced activation of 
transient receptor potential cation channels. Sci Rep 6(1):30639. https://doi.org/10.1038/srep30639

33. Han J, Koh YJ, Moon HR et al (2010) Adipose tissue is an extramedullary reservoir for functional hematopoietic stem and progenitor cells. Blood 115(5):957-964. https://doi.org/10.1182/ blood-2009-05-219923

34. Caporali A, Emanueli C (2009) Cardiovascular actions of neurotrophins. Physiol Rev 89(1):279-308. https://doi.org/10. 1152/physrev.00007.2008

35. Roux PP, Barker PA (2002) Neurotrophin signaling through the $p 75$ neurotrophin receptor. Prog Neurobiol 67(3):203-233. https://doi. org/10.1016/S0301-0082(02)00016-3

36. Bui NT, Konig HG, Culmsee C et al (2002) p75 neurotrophin receptor is required for constitutive and NGF-induced survival signalling in PC12 cells and rat hippocampal neurones. J Neurochem 81(3):594-605. https://doi.org/10.1046/j.1471-4159.2002.00841.x

37. Perlson E, Jeong GB, Ross JL et al (2009) A switch in retrograde signaling from survival to stress in rapid-onset neurodegeneration. J Neurosci 29(31):9903-9917. https://doi.org/10.1523/ JNEUROSCI.0813-09.2009

38. Sorensen B, Tandrup T, Koltzenburg M, Jakobsen J (2003) No further loss of dorsal root ganglion cells after axotomy in p75 neurotrophin receptor knockout mice. J Comp Neurol 459(3): 242-250. https://doi.org/10.1002/cne.10625
39. Apfel SC (2002) Nerve growth factor for the treatment of diabetic neuropathy: what went wrong, what went right, and what does the future hold? Int Rev Neurobiol 50:393-413

40. Schifitto G, Yiannoutsos C, Simpson DM et al (2001) Long-term treatment with recombinant nerve growth factor for HIV-associated sensory neuropathy. Neurology 57(7):1313-1316. https://doi.org/ 10.1212/WNL.57.7.1313

41. Khan N, Smith MT (2015) Neurotrophins and neuropathic pain: role in pathobiology. Molecules 20(6):10657-10688. https://doi. org $/ 10.3390 /$ molecules200610657

42. Chang DS, Hsu E, Hottinger DG, Cohen SP (2016) Anti-nerve growth factor in pain management: current evidence. J Pain Res 9:373-383

43. Cirillo G, Cavaliere C, Bianco MR et al (2010) Intrathecal NGF administration reduces reactive astrocytosis and changes neurotrophin receptors expression pattern in a rat model of neuropathic pain. Cell Mol Neurobiol 30(1):51-62. https://doi.org/10. 1007/s10571-009-9430-2

Publisher's note Springer Nature remains neutral with regard to jurisdictional claims in published maps and institutional affiliations. 